\title{
Variação sazonal das condições internas de colônias de Melipona marginata obscurior Moure, no Rio Grande do Sul, Brasil
}

\author{
Francine Von B. Borges \& Betina Blochtein
}

Faculdade de Biociências, Pontifícia Universidade Católica do Rio Grande do Sul. Avenida Ipiranga 6681, 90619-900 Porto Alegre, Rio Grande do Sul, Brasil. E-mail: fvborge@hotmail.com

\begin{abstract}
Seasonal variations in the internal condictions of colonies the Melipona marginata obscurior Moure, at Rio Grande do Sul, Brazil. The knowledge of the internal conditions of Melipona marginata obscurior Moure, 1971 colonies, through the year, is important for the understanding of the behavior and handling of the stingless bees. This work aims the biological study of the M. marginata obscurior in its natural environment, whith emphasis on the seasonal variation of the internal conditions of colonies. Four colonies were studied at Centro de Pesquisas e Conservação da Natureza Pró-Mata, in São Francisco de Paula, Rio Grande do Sul. It was valuated the nest volume, the diapause occurrence and duration, and the total number of combs and brood cells in the two last combs. For the four colonies the initial involucrum volume was similar, varying from 2.26 to 2.69 liter. In the final of the valuation, it was observed that the colony $\mathrm{A}$ volume was reduced to $5 \%$, while the others grow up $61 \%$ (colony $\mathrm{B}$ ), $84 \%$ (C) e $71 \%$ (D). From the monthly monitoring of the brood combs it was shown that diapause occurred in three colonies ( $B, C$ e D), while the colony $A$ remained ininterruptly with posture. The colonies ceased the construction of brood cells and posture of the queen during the autumn and restarted this activity on the final of the winter. It's suggested that diapause period variation ( 8 to 23 weeks) is determined by internal factors of the colonies. The maximal number of combs, registered during the spring and the summer, varied from 6 to 8 , while the number of the brood cells of the two last combs varied from 116 to 1190 cells. It was possible to recognize patterns, as well seasonal variations related to involucrum volume of the nest covering, to diapause occurrence and to number of the combs and brood cells on the two last combs. The seasonal variations of the internal conditions among the colonies were obvious and can be credited to intrinsic characteristics of the colonies.
\end{abstract} KEY WORDS. Brood cells; diapausa; involucrum volume; manduri; stingless bees.

RESUMO. O conhecimento das condições internas das colônias de Melipona marginata obscurior Moure, 1971, ao longo do ano, é importante para a compreensão do comportamento das abelhas sem ferrão e seu manejo. Visa-se o estudo da biologia de $M$. marginata obscurior em ambiente natural, com ênfase na variação sazonal das condições internas das colônias. Quatro colônias foram estudadas no Centro de Pesquisas e Conservação da Natureza PróMata, em São Francisco de Paula, RS. Avaliou-se o volume dos ninhos, a ocorrência e duração da diapausa e o número total de favos e de células de cria nos dois últimos favos. $\mathrm{O}$ volume do invólucro inicial das quatro colônias foi semelhante, variando de 2,26 a 2,69 litros. Ao final da avaliação observou-se que o volume do invólucro da colônia A reduziu 5\%, enquanto as demais cresceram $61 \%$ (colônia B), $84 \%$ (C) e 71\% (D). A partir do monitoramento mensal dos favos de cria constatou-se a ocorrência de diapausa em três colônias ( $B, C$ e $D)$ enquanto a colônia $A$ permaneceu com postura ininterruptamente. As colônias cessaram a construção de células de cria e postura da rainha durante o outono e reiniciaram esta atividade no final do inverno. Sugere-se que a variação do período de diapausa (8 a 23 semanas) seja determinada por fatores internos das colônias. $O$ número máximo de favos registrado durante a primavera e o verão variou de 6 a 8 , enquanto que o número estimado de células de cria dos dois últimos favos variou de 116 a 1190 . Foi possível reconhecer padrões, bem como variações sazonais, relacionados ao volume do invólucro dos ninhos, à ocorrência de diapausa e ao número de favos e de células de cria nos dois últimos favos. Variações sazonais das condições internas entre as colônias mostraram-se evidentes e podem ser creditadas a características intrínsecas das colônias.

PALAVRAS-CHAVE. Abelhas sem ferrão; células de cria; diapausa; manduri; volume do invólucro.

A população de uma colônia de abelhas está diretamente relacionada à postura da rainha fisiogástrica e às reservas ali- mentares, ou seja, existindo disponibilidade de alimento haverá possibilidade de manter um maior número de indivíduos e

Revista Brasileira de Zoologia 23 (3): 711-715, setembro, 2006 
isto serve de estímulo para a intensificação da atividade de postura. O número de células de crias representa a atividade de postura da rainha e a população da colônia (AIDAR 1996).

Em baixas temperaturas, os insetos dependem, para a sua sobrevivência, de adaptações bioquímicas e fisiológicas que resultam em períodos de quiescência ou diapausa. A quiescência é um estado de dormência, conseqüência imediata das condições adversas, enquanto que a diapausa caracteriza-se pela interrupção temporária do desenvolvimento ou da atividade reprodutiva (Nechols et al. 1999). Segundo Denlinger (2002), a inserção da diapausa em um ciclo de vida requer mecanismos de percepção do monitoramento ambiental e armazenamento desta informação até o cessar do desenvolvimento ou da atividade reprodutiva.

Em abelhas sociais a interrupção das atividades de postura das rainhas e as conseqüentes alterações comportamentais das operárias, relacionadas a fatores climáticos, foram documentadas por JULIANI (1967), IMPERATrIZ-FonSECA \& OLIVEIRA (1976), Kleinert-Giovannini (1982), Van Benthem et al. (1995), Freitas \& Wittmann (1997), Pick \& Blochtein (2002a) e Ribeiro et al. 2003).

O desencadeamento da diapausa reprodutiva em Plebeia remota (Holmberg, 1903) foi correlacionado com o fotoperíodo por Ribeiro et al. (2003). Estes autores enfatizam que a ocorrência deste fenômeno possibilita a presença das abelhas em regiões subtropicais, com condições ambientais adversas durante longos períodos. O conhecimento das condições internas das colônias, ao longo do ano, especialmente em regiões com estações climáticas diferenciadas, é fundamental para a viabilização de seu manejo.

Diferenças intraespecíficas nas condições das colônias de abelhas, sob as mesmas variações ambientais, induziram a caracterização das colônias, em fortes, médias e fracas. LACERDA et al. (1991) relacionam o comportamento de aprovisionamento de células de cria e o volume total das células com colônias fortes e fracas. Aiddr (1996), a partir da observação direta das colônias, atribui valores numéricos para representar o seu estado de desenvolvimento. Segundo KleInERT-GiovanNini \& IMPERATriz-FonSECA (1986), o diâmetro dos favos, assim como o tamanho e número de potes de alimento de Melipona marginata Lepeletier, 1836 podem proporcionar uma boa noção do estado geral da colônia. Hilário et al. (2000) classificam as colônias de Melipona bicolor bicolor Lepeletier, 1836 em fortes, médias ou fracas utilizando como critério o diâmetro médio dos favos de cria. Ribeiro et al. (2003) utilizaram o número estimado de abelhas e a quantidade de potes de alimento para definir colônias em fortes e fracas.

Segundo Ribeiro et al. (2003) em Plebeia remota, na fase de maior atividade na construção de células de cria e de postura, os favos geralmente não possuem invólucro. Entretanto, à medida que a diapausa reprodutiva se aproxima, nota-se que o invólucro aparece e o número e o espessamento dos trabiques de sustentação aumentam.

Conhecida como manduri, Melipona marginata obscurior Moure, 1971 é considerada a menor espécie do gênero Melipona
Illiger, 1806 (Nogueira-Neto 1970). Constrói seus ninhos em ocos de árvores de médio e grande porte em alturas superiores a $4 \mathrm{~m}$ (Kerr et al. 1996) e em paredões de taipa (Pirani \& CortopassiLAURINO 1994). M. marginata apresenta ampla distribuição, com registro para o estado da Bahia e regiões Sudeste e Sul do Brasil (Silveira et al. 2002), e seu limite sul de ocorrência foi registrado nas regiões Norte e Nordeste do Rio Grande do Sul (Wittmann \& Hoffmann 1990, Blochtein \& Harter-Marques 2004).

Devido à destruição de seus habitats e à exploração predatória do seu mel, M. marginata foi considerada ameaçada nos estados de Minas Gerais (CAmpos 1998) e Rio Grande do Sul (Blochtein \& Harter-Marques 2002).

Este estudo visa ampliar o conhecimento da biologia de Melipona marginata obscurior em ambiente natural, com ênfase na variação sazonal das condições internas das colônias, quanto à atividade reprodutiva das rainhas, à quantidade de favos de cria e ao volume do invólucro dos ninhos.

\section{MATERIAL E MÉTODOS}

O estudo foi desenvolvido, no Centro de Pesquisas e Conservação da Natureza Pró-Mata/PUCRS (Pró-Mata), no município de São Francisco de Paula, RS (29 $27^{\prime}$ S $/ 29^{\circ} 35^{\prime}$ S e $\left.50^{\circ} 08^{\prime} \mathrm{W} / 50^{\circ} 15^{\prime} \mathrm{W}\right)$ (BertoletTi \& Teixeira 1995).

A vegetação predominante é constituída pela Mata com Araucária, Mata Atlântica e Campos. A altitude varia entre 600 e 900m e o clima, segundo Köppen, é subtropical úmido, com regime pluviométrico oscilando entre 1750 e $2500 \mathrm{~mm}$ anuais (Ibge 1986, Bertoletti \& Teixeira 1995).

Quatro colônias de M. m. obscurior (A, B, C e D) foram obtidas na Serra Geral, Rio Grande do Sul, em sua área natural de distribuição, e transferidas para caixas de madeira de $3 \mathrm{~cm}$ de espessura e com medidas externas de 37 x 28 x $18 \mathrm{~cm}$, tampadas por placas de vidro transparente e cobertas com isopor e tampa de madeira. As colônias foram dispostas sobre uma bancada, no laboratório na sede do Pró-Mata, e as caixas foram interligadas, através da parede, ao exterior com mangueira plástica $(\varnothing 6 \mathrm{~mm})$.

As colônias foram revisadas quinzenalmente a partir da abertura do invólucro dos ninhos e da observação direta dos favos de cria, para avaliar suas condições internas, durante o período de agosto de 2002 a setembro de 2003. Para este procedimento foi utilizada iluminação fria (10W) com filtro vermelho (celofane), visando minimizar as mudanças no comportamento das abelhas.

A presença de favos de cria foi verificada mensalmente a fim de registrar a ocorrência e duração da diapausa nas colônias e o número total de favos de cria foi anotado a partir de observação direta.

O diâmetro dos dois últimos favos de cria em construção, de cada colônia, foi medido mensalmente com auxílio de paquímetro digital (Mitutoyo). Para estimar o número de células de cria dos favos utilizou-se a área da circunferência $\left(A=\pi \mathrm{D}^{2} / 4\right)$, considerando-se que a área média de uma célula foi $9,84 \mathrm{~mm}^{2}(\varnothing$ médio = 3,54 mm; $\mathrm{n}=97$; desvio padrão $=0,2153$ ). 
O invólucro dos ninhos de M. m. obscurior é constituído por lamelas irregulares de cerume, que ocultam os favos de cria e eventualmente potes de mel e pólen, cuja superfície externa configura uma semi-esfera. O volume do invólucro das colônias foi estimado a partir da fórmula do volume do elipsóide: 4/ $3 \pi$ (a.b.c), sendo a, b, e c, os raios dos três eixos medidos a partir das dimensões máximas (comprimento, largura e altura) de cada colônia (Fig. 1). O volume inicial do invólucro das colônias A, B, C e D foi semelhante, respectivamente 2,32, 2,69, 2,26 e 2,42 litros. Nos meses de março, maio, julho e setembro de 2003 o volume do invólucro das quatro colônias foi estimado e posteriormente analisado, considerando-se a condição de diapausa/postura pelas rainhas, usando-se a correlação de Pearson SPSS11.5 for Windows.

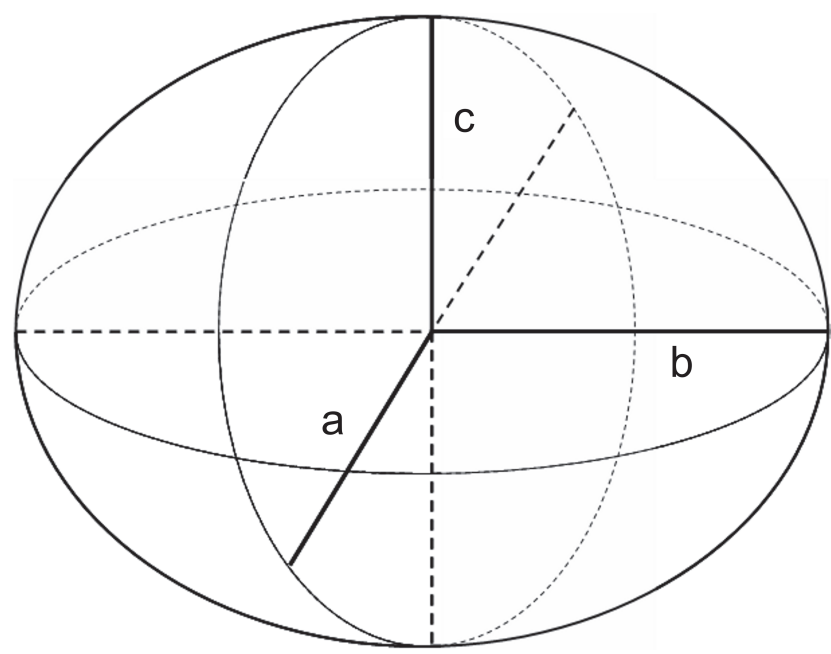

Figura 1. Desenho esquemático do invólucro e eixos mensurados.

\section{RESULTADOS E DISCUSSÃO}

A partir do monitoramento mensal dos favos de cria de M. marginata obscurior, procedido durante os 14 meses de estudo, constatou-se em três colônias de (B, C e D) a ocorrência de diapausa reprodutiva. Apenas a colônia A permaneceu em postura ininterruptamente (Fig. 2).

A colônia $C$ entrou em diapausa no início do outono (março), enquanto que a colônia B no meio da estação (abril) e a colônia D no inverno (junho). O término da diapausa, para as três colônias, ocorreu no inverno (agosto) (Fig. 2).

Um estudo realizado com Plebeia saiqui Holmberg, 1903, no mesmo local e sob condições climáticas semelhantes, revelou que as colônias cessaram a construção de células de cria e postura da rainha durante o outono e reiniciaram esta atividade no final do inverno (Рick \& Blochtein 2002b). Temporalmente os registros de diapausa reprodutiva em $P$. saiqui e em M. marginata obscurior apresentaram-se semelhantes.

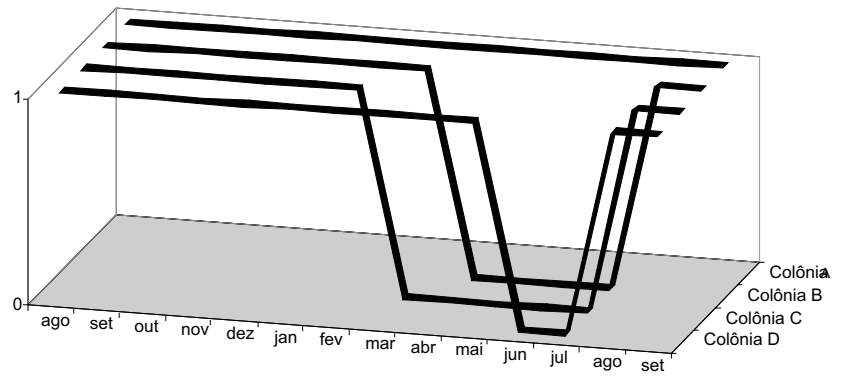

Figura 2. Períodos de postura (1) e de diapausa (0) de quatro colônias de Melipona marginata obscurior, de agosto de 2002 a setembro de 2003.

Considerando-se que a duração da diapausa foi de 8 (colônia D), 21(B) e 23(C) semanas, e que na colônia A não cessou o processo de oviposição, sugere-se que esta conspícua variação seja determinada por fatores internos das colônias.

Comportamento semelhante foi anotado para Plebeia saiqui que permaneceu em diapausa durante 10 a 24 semanas (Pick \& Blochtein 2002a).

Com relação à colônia A, que não interrompeu suas atividades reprodutivas ao longo do ano, sugere-se que o menor número de células de cria nos dois últimos favos, nos meses que precedem a diapausa das demais colônias, pode ter influenciado a continuidade da postura da rainha, caracterizando uma diapausa facultativa em M. marginata obscurior.

Não existem trabalhos realizados no Rio Grande do Sul a respeito da ocorrência de diapausa em espécies de Melipona. Nogueira-Neto (1970), comenta que Melipona quadrifasciata no Estado de São Paulo, às vezes paralisa temporariamente a construção de favos de cria no início do inverno ou mesmo no final do verão.

Durante o período de postura das rainhas de M. marginata obscurior, o número total de favos nas colônias variou de 1 a 6 na colônia A, de 2 a 6 na B, de 2 a 8 na $\mathrm{C}$ e de 2 a 7 na $\mathrm{D}$. $\mathrm{Na}$ colônia A foi verificado o maior número de favos durante a primavera e início do verão enquanto que nas demais colônias ocorreu no verão.

O número estimado de células de cria dos dois últimos favos da colônia A variou de 116 a 705, enquanto que nas demais esta variação foi de 194 a 1094 (colônia B), 246 a 1190 (colônia C) e 307 a 794 (colônia D) (Fig. 3).

Na primavera foi registrado o maior número de células de cria nos dois últimos favos e no verão o maior número de favos indicando que durante a primavera-verão ocorreu a maior atividade reprodutiva.

O volume do invólucro dos ninhos de M. marginata obscurior, nos meses de março, maio, julho e setembro de 2003, foi semelhante em três colônias (B, C e D) (Fig. 4). Em março (início do outono), o volume do invólucro nas quatro colônias estudadas era semelhante. Até meados de maio as colônias B, C e D mantiveram-se constantes, enquanto a colônia A diminuiu 

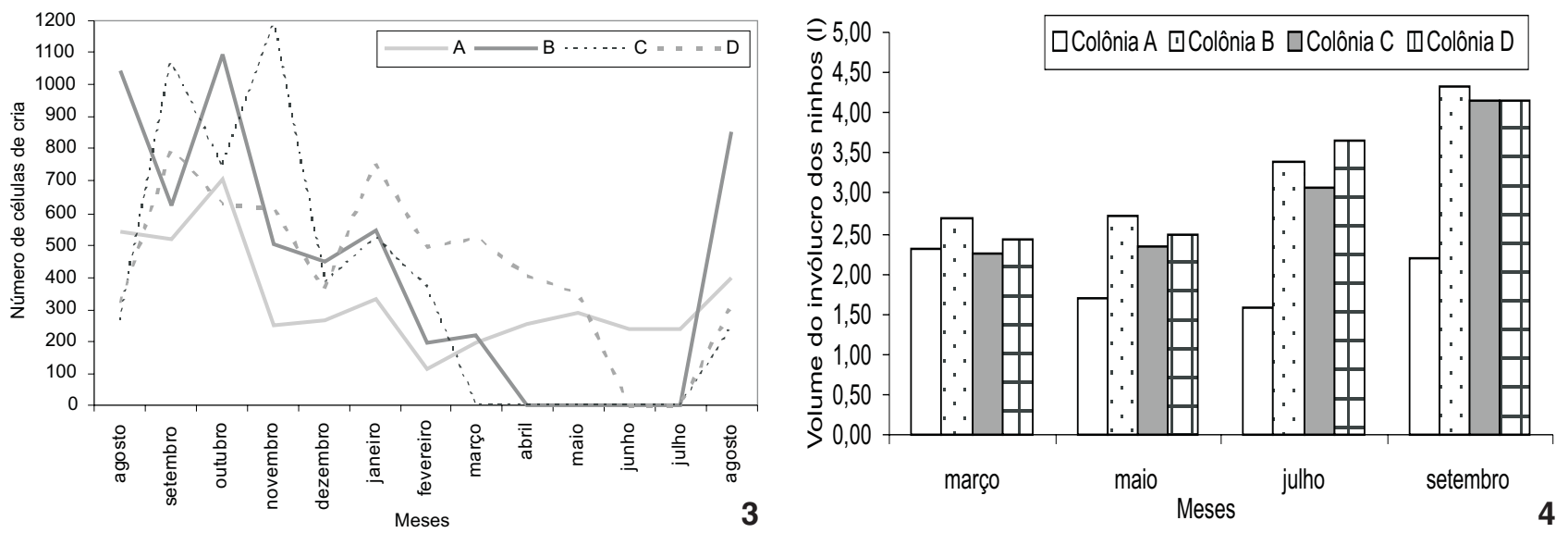

Figuras 3-4. (3) Estimativa do número de células nos dois últimos favos de cria de Melipona marginata obscurior, de agosto de 2002 a agosto de 2003; (4) volume do invólucro de quatro colônias de Melipona marginata obscurior, em 2003.

$27 \%$ do seu volume. A colônia A seguiu reduzindo o volume do invólucro $(8,9 \%)$ até julho, enquanto as colônias B, C e D aumentaram respectivamente de $25 \%$, 30\% e $47 \%$. No início da primavera, em setembro, notou-se aumento do volume das quatro colônias (Fig. 4). Durante todo o período observou-se, em relação ao volume inicial do invólucro, que a colônia A reduziu $5 \%$, enquanto as demais cresceram $61 \%$ (colônia B) $84 \%$ (C) e $71 \%$ (D) do volume total dos ninhos. $\mathrm{O}$ aumento significativo $(\mathrm{r}$ $=-0,579 / \mathrm{p}<0,05)$ do volume do invólucro das colônias B, C e D, no início do outono (março), corresponde ao período de prédiapausa reprodutiva. Com a redução das atividades externas e internas das colônias no outono-inverno, as abelhas mantém-se caracteristicamente no interior do invólucro (PICK \& BLOCHTEIN 2002a). Este comportamento sugere a necessidade de aumento de volume das construções de invólucro, além do espaço anteriormente ocupado pelos favos de cria. Segundo Riberro et al. (2003) colônias de $P$. remota mantém a estrutura do invólucro somente durante a diapausa e a funcionalidade deste está em oferecer condições de sobrevivência durante o inverno.

A partir do estudo das quatro colônias de M. marginata obscurior foi possível reconhecer padrões, bem como variações sazonais, relacionados à ocorrência de diapausa, ao número de favos e de células de cria nos dois últimos favos e ao volume do invólucro dos ninhos.

Diferenças das variações sazonais das condições internas, verificadas nas colônias de $M$. marginata obscurior, podem ser creditadas a características intrínsecas das colônias. A escassez de trabalhos anteriores sobre a avaliação do estado de colônias desta espécie, aliado a dificuldades metodológicas, indicam a necessidade de estudos que possam subsidiar avaliações do estado das colônias.

\section{REFERÊNCIAS BIBLIOGRÁFICAS}

AIDAR, D.S. 1996. A mandaçaia: biologia de abelhas, manejo e multiplicação artificial de colônias de Melipona quadri- fasciata Lep. (Hymenoptera, Apidae, Meliponinae). Ribeirão Preto, Sociedade Brasileira de Genética, 104p.

Bertoletti, J.J. \& M.B. Teixeira. 1995. Centro de Pesquisas e Conservação da Natureza Pró-Mata. Termo de Referência. Divulgações do Museu de Ciência e Tecnologia -UBEA/ PUCRS, Porto Alegre, 2: 1-47.

Blochtein, B. \& B. Harter-Marques. 2002. Hymenoptera, p. 2545. In: A.A.B. Marques; C.S. Fontana; E. Vélez; G.A. Bencke; M. SCHNEIDER \& R.E. Dos ReIs (Eds). Lista das espécies da fauna ameaçadas de extinção no Rio Grande do Sul. Decreto $\mathbf{n}^{\circ}$ 41.672, de 11 de Junho de 2002. Porto Alegre, FZB/MCTPUCRS/PANGEA, 52p.

Blochtein, B. \& B. Harter-Marques. 2004. Hymenoptera, p. 95109. In: A.A.B. Marques; C.S. Fontana; E. Vélez; G.A. Bencke; M. SCHNEIDER \& R.E. Dos ReIs (Eds). Livro Vermelho da fauna ameaçada de extinção no Rio Grande do Sul. Porto Alegre, FZB/MCT-PUCRS/PANGEA, 632p.

CAMPos, L.A. 1998. Melipona rufiventris Lepeletier, 1836, p. 560561. In: A.B.M. Machado; G.A.B. Fonseca; R.B.Machado; L.M.S. Aguiar; L.V. Lins (Eds). Livro Vermelho das espécies ameaçadas de extinção da fauna de Minas Gerais. Belo Horizonte, Biodiversitas, 605p.

Denlinger, D.L. 2002. Regulation of diapause. Annual Review of Entomology, Ohio, 31: 239-264.

Freitas, S.W. \& D. WitTMAnN. 1997. Poliginia temporária em Plebeia wittmanni Moure \& Camargo, 1989 (Hymenoptera: Apidae, Meliponinae). Biociências, Porto Alegre, 5 (2): 61-69.

Hilário, S.D.; Imperatriz-Fonseca, V. L. \& A. Kleinert-Giovaninni. 2000. Flight activity and colony strenght in the stingless bee Melipona bicolor bicolor (Apidae, Meliponinae). Revista brasileira de Biologia, Rio de Janeiro, 60 (2): 299-306.

IBGE. 1986. Levantamento de recursos naturais. Rio de Janeiro, IBGE, vol. 33, 796p.

Imperatriz-Fonseca, V.L. \& M.A.C. Oliveira. 1976. Observations on a queenless colony of Plebeia saiqui (Friese) (Hymenoptera, 
Apidae, Meliponinae). Boletim do Museu de Zoologia, da Universidade de São Paulo, São Paulo, 1: 299-312.

Juliani, L. 1967. A descrição do ninho e alguns dados biológicos sobre a abelha Plebeia julianii Moure, 1962 (Hymenoptera, Apidae). Revista Brasileira de Entomologia, Curitiba, 12: 31-58.

Kerr, W. E.; G. A. Carvalho \& V.A. Nascimento. 1996. Abelha uruçu - biologia, manejo e conservação. Belo Horizonte, Acangaú, 143p.

Kleinert-Giovannini, A. 1982. The influence of climate factors on flight activity of Plebeia emerina Friese (Hymenoptera, Apidae, Meliponinae) in winter. Revista Brasileira de Entomologia, Curitiba, 26 (1): 1-13.

Kleinert-Giovannini, A. \& V.L. Imperatriz-Fonseca. 1986. Flight activity and responses to climatic conditions of two subspecies of Melipona marginata Lepeletier (Apidae, Meliponinae). Journal of Apicultural Research, Cardiff, 25 (1): 3 8 .

LACERDA, L.M.; R. ZuCCHI \& F.S. ZuCOLOTO. 1991. Colony condiction and bionomic alterations in Geotrigona inusitata (Apidae, Meliponinae). Acta Biológica do Paraná, Curitiba, 20 (1-4): 109-123.

Nechols, J.R.; M.J. Tauber; C.A. Tauber \& S. Masaki. 1999. Adaptations to hazardous seasonal condictions: dormancy, migration and polyphenism, p. 159-200. In: HUFFAKER, C.B. \& A.P. Gutierrez (Eds). Ecological Entomology. New York, John Wiley \& Sons, $2^{\text {nd }}$ ed., 756p.

Nogueira-Neto, P. 1970. A criação de abelhas indígenas sem ferrão. Chácaras e Quintais, $2^{\mathrm{a}}$ ed., 365p.

Pick, R. \& B. Blochtein. 2002A. Atividade de coleta e origem floral do pólen armazenado em colônias de Plebeia saiqui (Holmberg) (Hymenoptera, Apidae, Meliponinae) no sul do Brasil. Revista brasileira de Zoologia, Curitiba, 19 (1): 289-300.

Pick, R. \& B. Blochtein. 2002в. Atividades de vôo de Plebeia saiqui (Holmberg) (Hymenoptera, Apidae, Meliponini) durante o período de postura da rainha e em diapausa. Revista Brasileira de Zoologia, Curitiba, 19 (3): 827-839.

Pirani, J.R. \& M. Cortopassi-Laurino. 1994. Flores e abelhas em São Paulo. São Paulo, Editora da Universidade de São Paulo, FAPESP, $2^{\text {a }}$ ed., 193p.

Ribeiro, M.F.; V. Imperatriz-Fonseca \& P.S.S. Filho. 2003. A interrupção da construção de células de cria e postura em Plebeia remota (Holmberg) (Hymenoptera, Apidae, Meliponini), p. 177-188. In: G.A.R. Melo \& I. Alves-dos-Santos (Eds). 2003. Apoidea Neotropica: homenagem aos 90 anos de Jesus Santiago Moure. Criciúma, Editora UNESC, 320p.

Silveira, F.A.; G.A.R. Melo \& E.A.B. AlmeidA. 2002. Abelhas brasileiras: sistemática e identificação. Belo Horizonte, F.A. Silveira, 253p.

Van Benthem, F.D.J.; V.L. Imperatriz-Foneseca \& H.H.W. Velthuis. 1995. Biology of the stingless bee Plebeia remota (Holmberg). Observations and evolutionary implications. Insectes sociaux, Paris, 42: 71-87.

Wittmann, D. \& M. Hoffmann. 1990. Bees of Rio Grande do Sul, southern Brazil (Insecta, Hymenoptera, Apoidea). Iheringia, Porto Alegre, 70: 17-43.

Recebido em 02.IX.2005; aceito em 18.VIII.2006. 